\title{
Correspondence
}

\section{Many ways to access hominin fossil finds}

Michael Cherry's perspective of elitist tourism at South Africa's Cradle of Humankind World Heritage Site in Gauteng does not take into account extensive efforts by scientists, the government and the private sector to bring a wider understanding of human evolution and our shared heritage to the South African public (Nature 523, 33; 2015).

Excavations of hominin fossils at the Malapa caves, viewed from an overhead structure (pictured), may need wealthy tourists to support access to the site, but plans include free school tours on at least one day each month. The Rising Star cave will be open as a nature and heritage reserve for an entry fee of just a few rands (12 rands is US $\$ 1$ ). A virtual lab at the Maropeng visitor centre will also allow people to watch Malapa fossils being prepared online.

Last year, 38,000 schoolchildren visited our education facilities at the active palaeontological site of Sterkfontein. The outreach programmes at the University of the Witwatersrand's Evolutionary Studies Institute, together with privately funded activities, reach about 200,000 more schoolchildren, most from disadvantaged backgrounds.

Public exhibitions of our fossil hominin treasures are held frequently at museums around South Africa, with up to 15 on display at any one time. The government and the University of the Witwatersrand have also gifted casts of Australopithecus sediba fossils to museums across Africa and around the world. Lee R. Berger University of the Witwatersrand, South Africa. lee.berger@wits.ac.za

\section{Initiatives to bridge faith and science}

Two initiatives aim to increase awareness and acceptance of science by US Christian communities, some of which

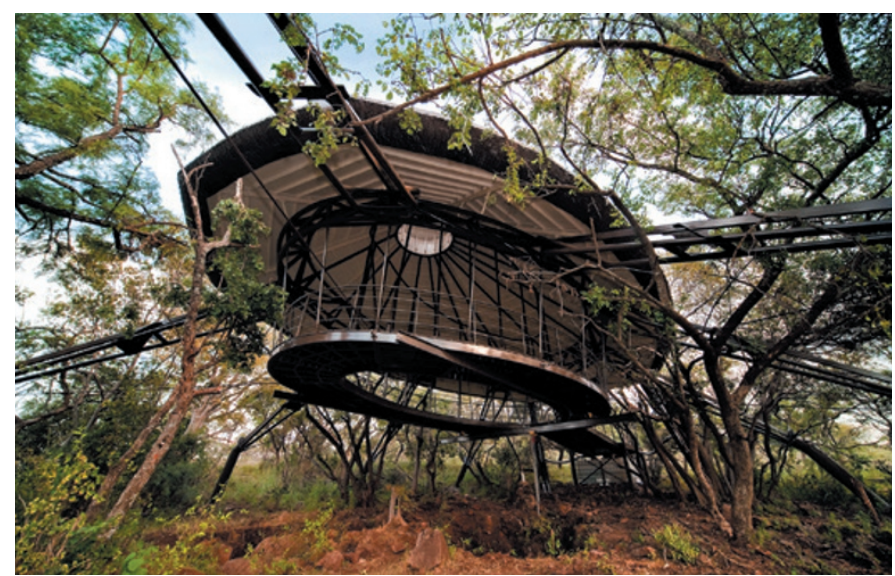

resist science-education efforts.

BioLogos (http://biologos. org) was founded in 2007 by

Francis Collins, then leader of the Human Genome Project, to encourage other Christians to accept evolution in the context of their faith. Trust and respect for Collins has been key to its success. Its grant programme has so far disbursed a total of US\$3.9 million to 37 faithscience partnerships.

In fostering dialogue between theologians and scientists who are Christians, BioLogos is forging a middle ground between presentations of science that are antagonistic towards faith and faith that will not accommodate science. Last month, for example, a BioLogos conference of scientists, theologians and pastors helped to articulate the overlap between theology and evolutionary theory (see go.nature.com/ovnpwb).

A programme by the American Association for the Advancement of Science takes a different approach, in partnership with the Association of Theological Schools (www. scienceforseminaries.org). Their pilot project has helped ten seminaries since 2013 to integrate science into the curriculum for training religious leaders. One seminary includes evolutionary biology in courses on biblical interpretation; others teach neuroscience, genetics or ecology within explorations of identity and environmental stewardship.
Science education is a public good that we as scientists should help to reinforce across all faiths with partnerships such as these. S. Joshua Swamidass Washington University in St. Louis, Missouri, USA. swamidass@wustl.edu

\section{Tree rings track climate trade-offs}

The information held in annual tree rings offers further insight into the potential of the world's forests to slow global warming (see Nature 523, 20-22; 2015). These data reveal fluctuations in growth rate caused by climatic, physiological and ecological factors, and provide long-term and spatially extensive records.

Tree-ring measurements provide information on functional trade-offs that can affect a tree's future, such as altered hydraulic and growth responses to the long-term rise in atmospheric carbon dioxide (see P. van der Sleen et al. Nature Geosci. 8, 24-28; 2015). And unlike data from remote sensing of forests and monitoring of tree diameters, tree-ring observations extend over centuries.

Such studies also mitigate the problems you mention of investigating small forest patches, because the size and number of research areas can be adjusted.

A relatively small percentage of ring-forming species in tropical forests and the fading record of tree-ring collections further back in time are impediments. Also, most existing tree-ring collections are not representative of trees that lived in the past (F. Babst et al. Oecologia 176, 307-322; 2014).

We suggest that combining retrospective tree-ring analysis, repeated forest inventory measurements and modelling studies could more effectively predict responses of the world's forests to climate change.

Pieter A. Zuidema Wageningen University, the Netherlands. David Frank Swiss Federal Research Institute WSL, Birmensdorf, Switzerland. david.frank@wsl.ch

\section{Universities aim for a sustainable future}

A survey of several European universities shows that corporate responsibility for the economic, social and environmental effects of commercial activities is slowly spreading to the non-profit sector in Europe - including to institutions of higher education.

The survey, undertaken in 2014, polled 73 members of the European University Association, representing 18 countries across a range of institutional age, size and ranking (see Y. Fassin in Proc. 26th Int. Assoc. Bus. Soc.; in the press). Of those 73 universities (response rate 11\%), 82\% had incorporated sustainability and the European Commission's corporate social responsibility recommendations into their development strategies; 70\% were already reporting on their initiatives.

The survey revealed that these universities tend to emphasize sustainable development over social responsibility. Perhaps because social responsibility is a given for universities, sustainability for future generations of students seems to hold more sway with university management.

Yves Fassin Ghent University, Belgium. yves.fassin@ugent.be 